\title{
Environmental Policy and Induced Technological Change: Evidence from Automobile Fuel Economy Regulations
}

\author{
Takahiko Kiso $^{1}$ (D)
}

Accepted: 7 May 2019 / Published online: 21 May 2019

(c) The Author(s) 2019

\begin{abstract}
This paper investigates whether environmental or energy-efficiency regulations induce innovations in relevant technologies through focusing on the tightening of Japanese fuel economy regulations in the 1990s and the early 2000s. Unlike previous studies that analyze patent data, I use vehicle-level specification data for 1985-2004 to estimate whether regulatory pressure accelerated technological progress in fuel efficiency. I compare Japanese automakers with selected American and European automakers in a difference-in-differences framework. The estimation results provide strong evidence for induced technological change: conditional on other vehicle attributes and the production cost, the regulatory tightening induced at least a 3-5\% improvement in the average Japanese vehicle's fuel economy relative to a counterfactual case with no regulatory change, an effect which would have taken at least 4-7 years to be realized with no pressure from fuel economy regulations or fuel prices.
\end{abstract}

Keywords Vehicles $\cdot$ Fuel economy regulations $\cdot$ Induced innovation $\cdot$ Technological change

JEL Classification $\mathrm{L} 62 \cdot \mathrm{O} 30 \cdot \mathrm{Q} 48 \cdot \mathrm{Q} 55 \cdot \mathrm{Q} 58$

\section{Introduction}

Understanding how government policies, including environmental and energy-efficiency regulations, affect innovations in "clean" technologies is crucial to sustaining economic growth without causing serious environmental degradation (Acemoglu et al. 2012). The induced innovation hypothesis, first specified by Hicks (1932) and more recently restated in relation to environmental policy by Porter (1991), suggests that environmental regulations, along with resource prices, can be a source of technological change. According to the hypothesis, to comply with environmental or energy-efficiency standards, firms will allocate more resources into developing relevant technologies and/or lowering the production

Takahiko Kiso

tkiso@abdn.ac.uk

1 Department of Economics, University of Aberdeen, Edward Wright Building, Dunbar Street, Aberdeen AB24 3QY, UK 
costs of these technologies. This leads to advances in environmental or energy-efficient technologies ("induced" or "directed" technological change) and lowers the compliance costs.

This paper empirically tests the hypothesis in the context of road transport, one of the biggest sources of greenhouse gas emissions that makes up $10 \%$ of global emissions in 2010 and 23\% of US emissions in 2016, for example (Intergovernmental Panel on Climate Change 2014; Environmental Protection Agency 2018). Specifically, I estimate how Japanese automakers' production possibility frontier (PPF) between fuel economy and other relevant attributes (e.g., horsepower) improved from the mid-1980s to the early 2000s. Japanese fuel economy regulations started to be tightened in the 1990s, preceding the tightening or introduction of similar regulations in other regions, including the US and the EU. Using vehicle characteristics data (rather than patent data as in almost all the previous studies on induced innovation in environmental or energy-efficient technologies), I investigate whether the technological progress achieved by Japanese automakers accelerated after the regulatory tightening.

Previous studies show empirical evidence of technological change induced by environmental/energy-efficiency regulations or energy/fuel prices. ${ }^{1}$ Newell et al. (1999) analyze technological change in energy efficiency based on product-level data for air conditioners and water heaters in the US market, finding that the direction of technological change is responsive to energy prices for some products and that government energy efficiency standards also have a significant impact on the average energy efficiency of the product menu. Based on US patent data, Popp (2002) studies the impact of energy prices on innovations in energy-saving technologies, noting a strong, positive impact of energy prices on the number of new patents. Similarly, Popp (2006) uses patent data from the US, Japan, and Germany to examine the innovation in and diffusion of air pollution control equipment, observing that innovation responds to regulatory pressure. There are other studies in the literature, such as Lanjouw and Mody (1996), Jaffe and Palmer (1997), Brunnermeier and Cohen (2003), Nesta et al. (2014), and Calel and Dechezleprêtre (2016), that also use patent data to estimate the degree of induced innovation.

Given the economic and environmental significance of the auto industry, several studies look particularly into (induced or overall) technological change in vehicle fuel economy or emission control technologies. Berry et al. (1996) estimate automakers' production cost functions for the period 1972-1982, when gasoline prices increased rapidly and vehicle emission and fuel economy standards were tightened. Using plant-level cost data, they show that (per-vehicle) production costs increased over the period, even after controlling for changes in vehicle characteristics. Additionally, by analyzing patent data, they observe that patent applications linked to combustion engines increased significantly, implying faster technological progress. An important implication of the results of Berry et al. (1996) is that rising gasoline prices or tightened regulations lead simultaneously to increased production costs and technological progress, both of which can improve fuel economy. Knittel (2011) examines fuel economy trends in the US, using vehicle-level specification data and an empirical framework which is similar to this paper's in that fuel economy is regressed on other vehicle attributes and firm and time fixed effects. He focuses on the overall rate of technological progress (part of which may be induced by government regulations and fuel

\footnotetext{
1 Recent surveys of the theoretical or empirical literature on induced innovation include Jaffe et al. (2003), Vollebergh (2007), Popp et al. (2010), Carraro et al. (2010), Ambec et al. (2013) and Dechezleprêtre and Sato (2017).
} 
prices) and finds steady trends of fuel economy improvement (conditional on other vehicle attributes and firm fixed effects) in the US between 1980 and 2006. According to his estimates, the early 1980s, when gasoline prices were high and the US Corporate Average Fuel Economy (CAFE) standards were tightened, saw the fastest pace of improvement, which likely resulted not only from (autonomous and induced) technological progress but also from the increased production costs associated with fuel economy, as suggested by Berry et al. (1996). ${ }^{2} \mathrm{He}$ also states that his estimates may be biased because these incremental production costs are unobservable and thus omitted. ${ }^{3}$ Haščič et al. (2009) use international data on patent activity to show that environmental regulations and higher fuel prices encourage innovations in automotive emission control technologies for local air pollutants. Based on US patent data on energy-efficient automotive technology, Crabb and Johnson (2010) measure technological progress induced by high oil prices and the CAFE standards, finding robust empirical evidence for the impact of oil prices, but none for the CAFE standards. By analyzing firm-level patent data from multiple countries, Aghion et al. (2016) observe that "clean" innovations in the auto industry (for example, innovations associated with electric, hybrid, and hydrogen vehicles) are stimulated by high fuel prices.

These previous studies on induced innovation in energy efficiency or pollution control are based on patent data (except for Newell et al. (1999) on air conditioners and water heaters), whereas I examine induced innovation by using product characteristics (vehicle specifications) data. In this regard, this paper is similar to Newell et al. (1999) and Knittel (2011) discussed above. While patents are an essential part of innovation, energy efficiency patents themselves do not reduce energy consumption or carbon emissions; they must be adopted in marketed products to achieve this goal (technology adoption and commercialization). It is, therefore, worthwhile to measure the extent of induced technological change that materializes in marketed products. I intend to fill the gap in the literature between induced innovation as measured by patent counts, which has been empirically confirmed by many studies, and improved environmental performance or energy efficiency as observed in actual product characteristics.

An issue in estimating induced technological change using product characteristics data is how to distinguish it from the effect of increased production costs. The findings by Berry et al. (1996), as described above, suggest that both technological progress and increased production costs presumably helped improve fuel economy after the tightening of the Japanese regulations. However, it is practically impossible to observe how much is spent on various fuel economy-improving systems and devices of each vehicle (hence the omission of the costs by Knittel (2011)).

\footnotetext{
2 Autonomous technological progress is what occurs irrespective of market conditions such as fuel prices or environmental regulations.

${ }^{3}$ Knittel (2011) interprets the estimated trend of fuel economy improvement as the effect of technological progress despite the possible bias due to the omission of the production costs related to fuel economy. For robustness checks, he estimates several regressions, each of which includes an additional explanatory variable related with a vehicle's price as a proxy for the production costs devoted to its fuel economy, and argues that the bias is likely small. Nevertheless, the negative coefficient estimates for the vehicle price variables in these regressions imply that more expensive vehicles are less fuel efficient conditional on other explanatory variables. This makes it unclear if these vehicle price variables are good proxies for the fuel economy costs: other things equal, additional production costs spent for a vehicle's fuel economy should make it more fuel efficient. Since the production costs related to fuel economy $\left(C^{1}\right.$ in his theoretical model) are just part of the total production costs of a vehicle $\left(C^{1}+C^{2}\right.$ in his theoretical model), it may be the case that the vehicle price is a good proxy for $C^{1}+C^{2}$, but not for $C^{1}$, the part that needs to be controlled for in estimating technological progress in fuel efficiency.
} 
This paper intends to address the problem by analyzing vehicles produced by Japanese automakers and sold in the US, with vehicles produced by selected American and European automakers and sold in the US serving as a control group. There are a few key observations for this research design. First, these non-Japanese automakers' sales in the Japanese market were so small that the Japanese fuel economy regulations were unlikely to affect their technology. That is, only Japanese automakers potentially experienced innovations induced by the Japanese regulations. Second, the Japanese regulations were the main factor in inducing technological progress in fuel efficiency during the period of the analysis (1985-2004). Fuel economy regulations in the US and the EU remained almost unchanged or had not come into effect in this period. Fuel prices were relatively stable or slowly decreasing in most countries, including Japan, the US, and the EU. This implies that, other than the Japanese regulations, there were few, if any, factors that would have induced technological progress in fuel efficiency in these markets during the period. Third, the paper's regression analysis indicates that Japanese vehicles sold in the US market were not subject to the added production costs resulting from the Japanese regulations. Then, the regulationinduced innovation, which presumably benefited the production of these vehicles too, can be observed in them without being confounded by the induced extra costs.

Under these circumstances, the paper's empirical strategy, which compares the US-market fleet of Japanese automakers (the treatment group) with that of selected American and European automakers (the control group) in a difference-in-differences framework, reveals (a lower bound of) the effect of technological progress induced by the Japanese regulations. This is because (1) comparing the two groups in a difference-in-differences framework will "difference out" the trends that are common to both groups, such as autonomous technological change, and (2) the effects specific to Japanese vehicles in the treatment period are attributable to the technological progress (rather than the incremental production costs) induced by the Japanese regulations. In practice, the effect of induced innovation estimated from this framework should be interpreted as a lower bound of the actual effect for a few reasons that are discussed in Sect. 4, such as the possibility that an induced shift of a Japanese automaker's PPF might not fully transfer to the production process of its US-market fleet. This empirical strategy is similar to the one taken by Popp (2006) and Aghion et al. (2016) in the sense that induced innovation is identified by exploiting international differences in environmental regulations or fuel prices and the variation across firms in the relative importance of different national markets in their sales.

Using the US Environmental Protection Agency's fuel economy test data for each vehicle configuration sold in the US from the 1980s to the 2000s, I estimate how the fuel economy of the vehicles in the treatment and control groups improved over time, conditional on other attributes such as horsepower and engine size. The analysis reveals whether the Japanese automakers' rate of improvement in (conditional) fuel economy accelerated relative to that of the non-Japanese automakers once the tightened regulations in Japan started to affect the former (but not the latter) in the second half of the 1990s.

The estimation results provide evidence of substantial induced technological progress. Across different settings, the estimated lower bounds for the effect of induced innovation are generally in the range of 3-5\% (with significance at the $5 \%$ or $10 \%$ level in most cases). That is, induced technological change enabled the average vehicle to be at least 3-5\% more fuel efficient, holding other vehicle attributes and the production cost constant and setting aside the autonomous factors (e.g. autonomous technological change) that would have occurred even in a counterfactual case of no regulatory change. Stated differently, the effect of induced innovation is at least as large as what would have resulted from such autonomous factors over 4-7 years even with no inducement from fuel economy regulations or 
fuel prices. Thus, this paper illustrates that new patents induced by government regulations, which are analyzed and evidenced by the previous studies, are indeed adopted in actual products sold in the market and contribute to significant improvements in environmental performance or energy efficiency.

The rest of the paper is organized as follows. Section 2 provides a theoretical framework to analyze the determinants of automotive fuel economy. Section 3 describes fuel economy regulations and trends in Japan. Section 4 explains the data used for the empirical analysis and discusses the empirical framework. Section 5 presents the estimation results, and Sect. 6 concludes the study.

\section{A Model of Induced Technological Change in Fuel Economy}

Let us consider the following model of an automaker's production cost function for the fuel economy of a vehicle:

$$
c=F_{t}^{m}(\mathbf{x}, e),
$$

where $m$ and $t$ index a manufacturer and time, respectively; $e$ is the vehicle's fuel economy (miles per gallon, or mpg); $\mathbf{x}$ is a vector of other vehicle attributes (e.g., horsepower and engine displacement) that affect fuel economy and are valued by consumers due to their preferences for non-fuel-economy aspects of a vehicle; and $c$ is the minimum cost of producing a vehicle with $(\mathbf{x}, e)$, as derived from the manufacturer's cost minimization. This function corresponds to the function $C^{1}$ of Knittel (2011).

Given $\mathbf{x}$, improving $e$ requires more or better fuel economy-improving systems/devices, which increase the fuel economy cost, $c$ (i.e., $\left.\partial F_{t}^{m}(\mathbf{x}, e) / \partial e>0\right) .{ }^{4}$ For example, a vehicle with a six-speed transmission would be more fuel efficient than a vehicle with the same characteristics except for having a five-speed transmission, but increasing the number of gears from five to six would incur additional costs.

Assuming Eq. (1) is solvable for $e$, the paper will focus on the following function:

$$
e=G_{t}^{m}(\mathbf{x}, c) .
$$

The function $G_{t}^{m}$ (or equivalently $F_{t}^{m}$ ) represents the level of automaker $m$ 's fuel efficiency technology at time $t$ and is the primary focus of the paper. The function describes how fuel efficiency $(e)$ relates to the vehicle characteristics that affect $e$, such as vehicle weight and horsepower, and fuel economy-improving systems/devices as summarized in $c{ }^{5}$ In other words, $G_{t}^{m}$ represents automaker $m$ 's PPF between $e$ and $\mathbf{x}$, given $c$. In this framework, technological change is equivalent to a shift of $G_{t}^{m}$ over time as in Fig. 1, which shows the

\footnotetext{
4 Specifically, National Research Council (2002) lists three categories of fuel economy improving devices/ systems. The first category improves the energy efficiency of engines by reducing friction and other mechanical losses or by improving the processing and combustion of fuel and air (e.g., variable valve timing, cylinder deactivation, and direct injection engines). The second category improves the efficiency of the transmission system where power is transmitted from the engine to the drive shaft or axle (e.g., six-speed automatic transmissions and continuously variable transmissions). The third category relates to other ways of improving fuel economy such as aerodynamic drag reduction, rolling resistance reduction and integrated starter/generator systems. The Council also includes novel vehicle concepts such as hybrid electric vehicles in the third category.

5 The theoretical background for including the production cost $(c)$ in the technology function can be found in, for example, Alexander and Mitchell (1985), Triplett (1985) and Newell (1997).
} 


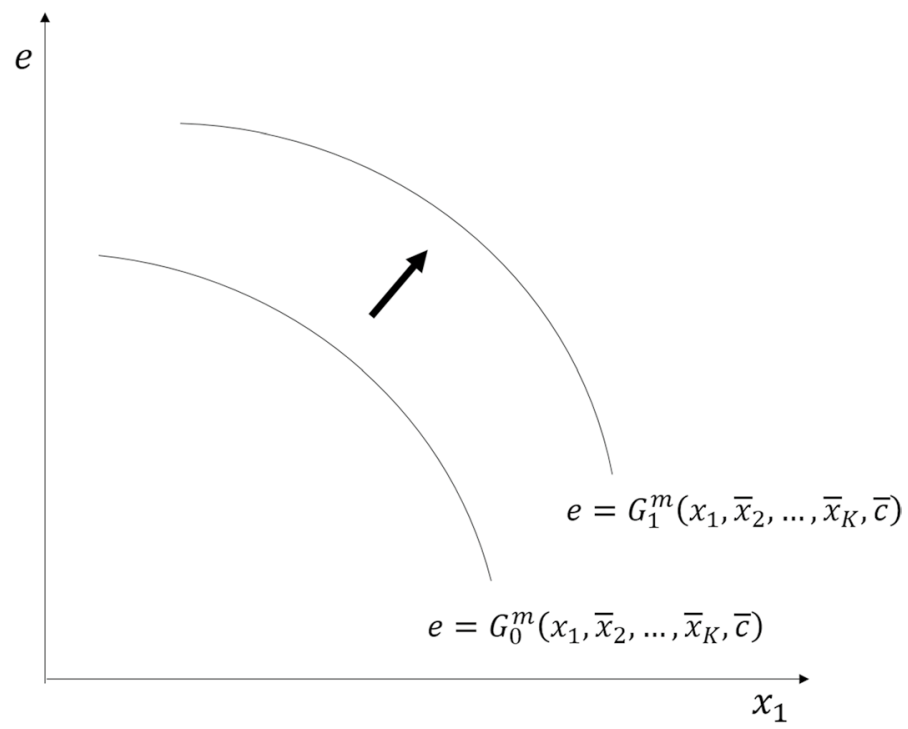

Fig. 1 Technological progress as an outward shift of the production possibility frontier

trade-off between $e$ and $x_{1}$ conditional on the other attributes in $\mathbf{x}$ and $c$. The induced innovation literature considers two sources of technological change (e.g., Newell et al. 1999): one is autonomous technological change that would occur regardless of market conditions, and the other is induced technological change that results from changes in market conditions such as regulations and resource prices. Therefore, induced technological change is regarded as a faster shift of $G_{t}^{m}$ when government regulations are tightened or fuel prices go up.

This model indicates three determinants of a vehicle's fuel economy: other vehicle attributes that affect fuel economy $(\mathbf{x})$, the costs spent on "producing" its fuel economy (c), and the level of the producer's fuel efficiency technology (the function $G$, where super/ subscripts are omitted for brevity). The observed fuel economy is the combined outcome of these factors. It is important to distinguish the first two factors from the last: a change in $e$ $(\Delta e)$ due to a change in $\mathbf{x}$ or $c(\Delta \mathbf{x}$ or $\Delta c)$ is a shift along the PPF, while $\Delta e$ due to a change in $G(\Delta G)$ is a shift of the PPF.

Fuel economy regulations and fuel prices are two important conditions that lead automakers to adjust $e$ by changing $\mathbf{x}, c$, and $G$. Facing new fuel economy regulations or stronger consumer demand for fuel economy because of increased fuel prices, they improve fuel economy by adjusting $\mathbf{x}$ or $c$ or by advancing $G$. Reducing vehicle weight or engine size/power is the easiest way to improve fuel economy, although it may not be welcomed by consumers. Indeed, the introduction of the US CAFE standards in 1978 brought a significant reduction in vehicle weight and power (Environmental Protection Agency 2019). In addition, new government regulations or high fuel prices are likely to increase the fuel economy cost $(c)$. For example, the fuel economy regulations established by the Obama administration in 2009 were expected to increase the cost of the average car by $\$ 1300$. Similarly, Berry et al. (1996) estimate automakers' production cost functions for 1972-1982 and find that the tightened emission standards and increasing gasoline prices added to vehicle production costs. Third, as suggested by the induced innovation hypothesis, regulatory 


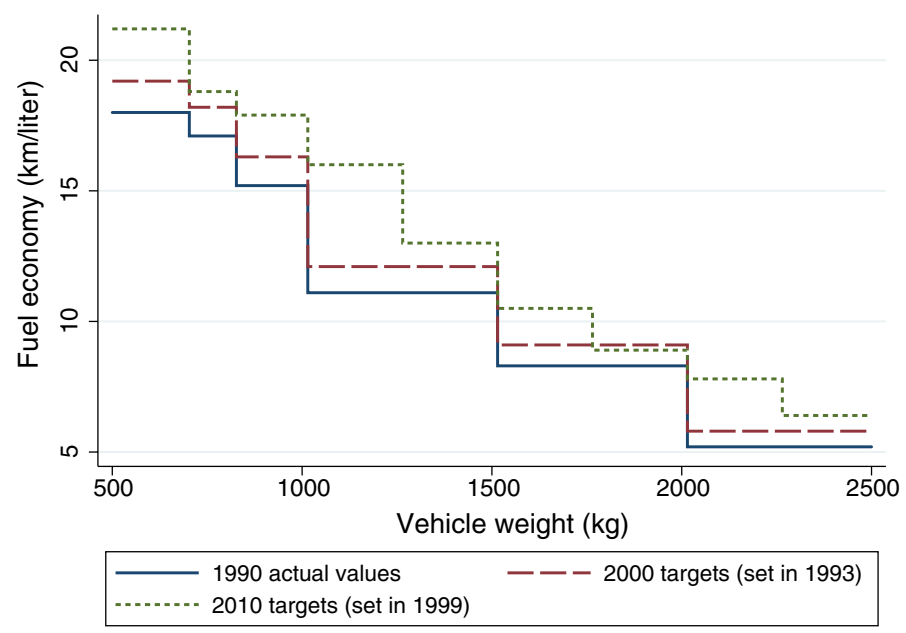

Fig. 2 Japanese fuel economy targets for 2000 and 2010

pressure or strong demand for better fuel economy may induce more R\&D activities in fuel efficiency and shift $G$ outwards. To empirically investigate the effect of fuel economy regulations on technological change, we need to separate these three effects and extract the information on the shift of $G$ alone. This would be relatively straightforward if vehiclelevel, repeated cross-section data are available for $e, \mathbf{x}$, and $c$ over time. In this case, the shift of $G$ can be estimated by regressing $e$ on $\mathbf{x}$ and $c$ along with time trend variables.

An empirical challenge is that $c$ is unobservable. It is practically impossible to know how much is spent on each vehicle's fuel economy. If we omit $c$ and just regress $e$ on $\mathbf{x}$ and time trend variables for a period when $c$ is systematically changing over time, we cannot distinguish the effect of $\Delta G$ from that of $\Delta c$. Therefore, we cannot conclude whether the observed fuel economy improvements (after controlling for $\Delta \mathbf{x}$ ) are due to technological progress or production cost changes. For a period of regulatory tightening, ignoring $c$ is likely to overestimate technological progress if automakers also increase $c$ over time to meet the targets. This paper addresses the issue by examining Japanese vehicles sold in the US market, which the analysis in Sect. 4 indicates are not subject to the cost increases induced by the Japanese regulations.

\section{Fuel Economy Regulations and Trend in Japan}

Figure 2 summarizes the Japanese fuel economy targets for the years 2000 and 2010. The targets vary by vehicle weight class, and an automaker's average fuel economy for each weight class in (and after) an implementation year (2000 or 2010) must exceed the corresponding target value. A weight class is represented by a flat section of each step function in Fig. 2. The year 2000 targets were established in January 1993, aiming to improve the fleet-average fuel economy by $8.5 \%$ in 2000 relative to 1990 . The year 2010 targets were set in March 1999 to improve the fleet-average fuel economy by $23 \%$ in 2010 relative to 1995. 


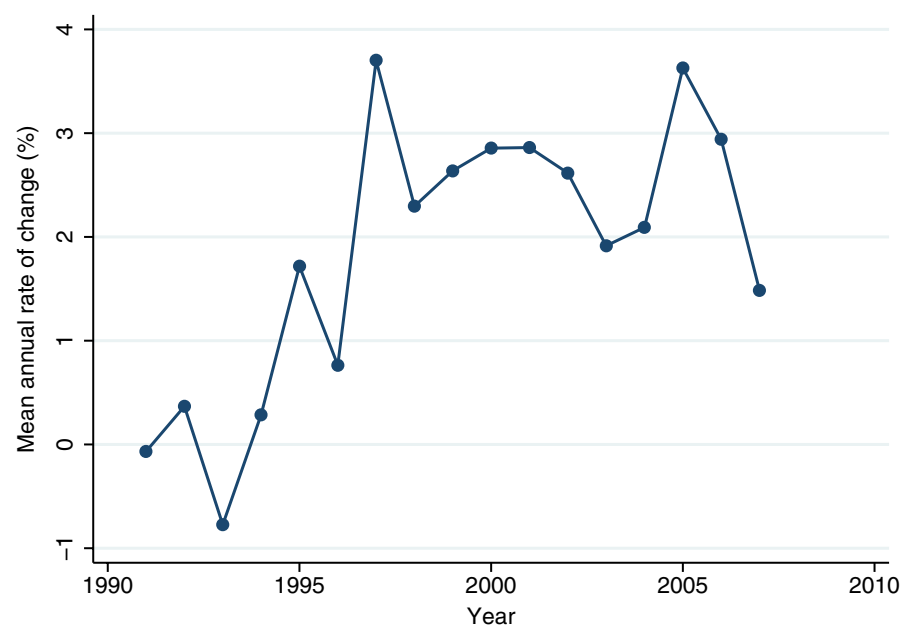

Fig. 3 Fuel economy improvement in Japan (1991-2007). Note: For each year, the figure shows the average (annual) rate of fuel economy improvement over the seven weight classes for which the 2000 and 2010 standards were binding

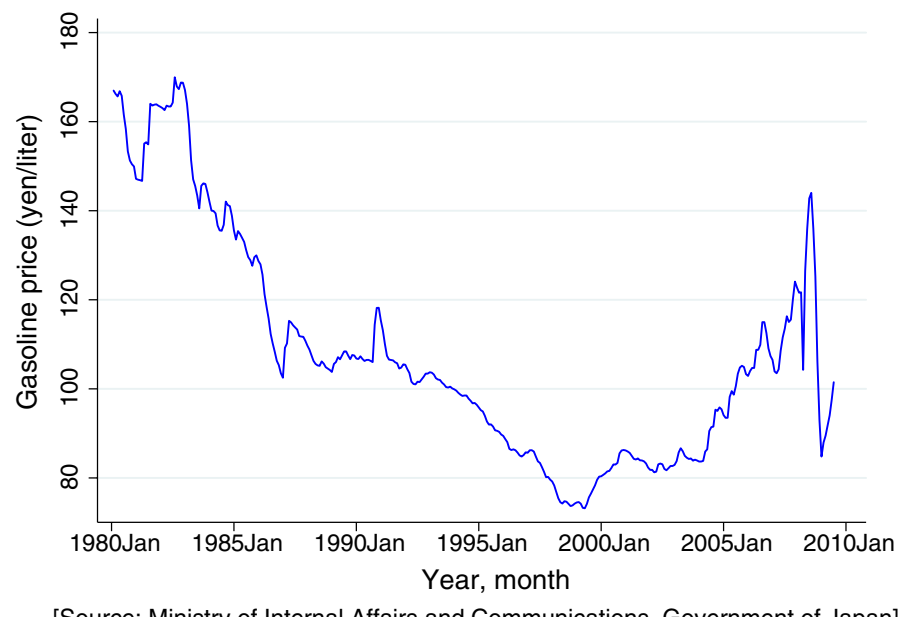

Fig. 4 Regular gasoline prices per liter in Japan (in 2005 yen)

For the period 1991-2007, Fig. 3 plots the average (annual) rate of fuel economy improvement over the seven weight classes for which the 2000 and 2010 regulations were binding. ${ }^{6}$ The figure shows that much faster improvement occurred after the late 1990s than before. Given that gasoline prices in Japan slowly declined in the 1990s (Fig. 4), the

\footnotetext{
${ }^{6}$ The values in the figure are calculated from the fuel economy data published by the Ministry of Land, Infrastructure and Transport.
} 
new fuel economy standards are most likely the primary factor to explain the fuel economy trend. Even though the targets did not come into force until 2000, fuel economy began to pick up in advance (instead of having a large jump in 2000). This is because of vehicle model cycles: typically, the fuel economy of a vehicle model is significantly improved when it is fully redesigned (usually every 4-6 years), and this timing differs across models.

Although Fig. 3 indicates the effect of the fuel economy regulations, it may not be fully explained by induced technological progress. As discussed above, when regulations are tightened, fuel economy improvements may come from three factors: reducing $\mathbf{x}$, increasing $c$, and advancing $G$. Since Fig. 3 is based on the average rate of fuel economy improvement over different vehicle weight classes and vehicle weight is a crucial element of $\mathbf{x}$, the effect of $\Delta \mathbf{x}$ over time is controlled for (at least partially). Nevertheless, the improvement rate in Fig. 3 contains the effects of both $\Delta G$ and $\Delta c$. Therefore, it is uncertain from the figure alone how much of the improvement can be attributed to technological change $(\Delta G)$.

\section{Empirical Framework}

The overall empirical framework of this paper is to estimate the induced technological change due to the Japanese fuel economy standards by analyzing vehicles that were produced by Japanese automakers (specifically, Honda, Isuzu, Mazda, Mitsubishi, Nissan, Subaru, Suzuki, and Toyota) and sold in the US. These standards may have induced both an upward shift of $G$ and increases in $c$ for these producers' Japanese-market fleet, making it hard to identify the effect of the former. The regression analysis below indicates that their US-market models, on the other hand, were not subject to $\Delta c$ that was induced by the Japanese regulations. Thus, Japanese vehicles in the US market help us identify (a lower bound of) the effect of induced technological progress. The following subsections discuss more details of the empirical framework.

\subsection{Data}

I use vehicle specification data taken from the US Environmental Protection Agency's annual "Fuel Economy Test Car List Data" for model years (MYs) 1985-2004 (1985-2009 for some regressions). This dataset contains the results of all the fuel economy tests conducted under the CAFE standards, providing the information on fuel economy and other relevant attributes for almost all the vehicle configurations sold in the US new light-duty vehicle market each year. Note that a vehicle model (e.g., the Toyota Camry) in a given year usually has a number of configurations which vary in weight, engine size, transmission type, and so on. The dataset typically includes multiple configurations per model. In the following analysis, I focus on gasoline-engine vehicles and thus exclude hybrid, electric, and diesel vehicles because their market shares were very small during the period of my analysis (1985-2004). Lastly, a particular vehicle configuration usually remains on the market for several years (i.e., there are no changes in its specifications for several years), thus appearing in the dataset over multiple years. To highlight the latest PPF, I use only the first observation for each vehicle configuration and drop the observations in subsequent years. 


\subsection{Estimation Strategy}

Simply put, my estimation strategy is a difference-in-differences framework in which I compare the Japanese automakers with selected American and European automakers before and after the Japanese fuel economy regulations started to affect the former (but not the latter). Overall, this is similar to the strategy used by Popp (2006) and Aghion et al. (2016). These papers note international differences in environmental regulations or fuel prices and the heterogeneity across manufacturers (of air pollution control equipment for Popp (2006) and of vehicles for Aghion et al. (2016)) in the relative importance of different geographic markets in their sales. Under these circumstances, firms face different levels of regulatory pressure and the papers exploit this variation to identify induced innovation.

Specifically, my strategy can be summarized by the following two-way fixed effects model:

$$
\ln e_{i m t}=\alpha_{t} J_{m t}+\gamma^{\prime} \mathbf{x}_{i m t}+\delta_{m}+\eta_{t}+\varepsilon_{i m t},
$$

where the subscripts imt represent vehicle configuration $i$ produced by manufacturer $m$ in year $t$, and $e_{i m t}$ is fuel economy (miles per gallon). On the right-hand side, $J_{m t}$ is a dummy variable for vehicles produced by the Japanese automakers in year $t$, and $\mathbf{x}_{\text {imt }}$ is a vector of other attributes that affect fuel economy and are valued by consumers due to their preferences for non-fuel-economy aspects of the vehicle. More specifically, $\mathbf{x}_{i m t}$ consists of the natural logarithms of weight $(\mathrm{kg})$, horsepower $(\mathrm{hp})$, and engine displacement (liter) as well as the squared and interaction terms of the three logarithms (i.e., the translog form), and dummy variables for transmission types, drivetrain types, and the light-duty truck category. ${ }^{7}$

Also included are manufacturer and year fixed effects $\left(\delta_{m}\right.$ and $\left.\eta_{t}\right)$. Thus, $\alpha_{t}$ measures the average difference in fuel efficiency between the Japanese and non-Japanese vehicles in year $t$, conditional on other vehicle attributes and manufacturer and year fixed effects. The effect of $\Delta G$ or $\Delta c$ over time is reflected in the time trend of $\eta_{t}$ to the extent that it is common to all vehicles/automakers (e.g., autonomous technological change), and in the time trend of $\alpha_{t}$ to the extent that it is specific to the Japanese vehicles/automakers only. By plotting $\alpha_{t}$ over time, I investigate whether $\alpha_{t}$ shifts upward for the period during which the tightened Japanese regulations influenced the Japanese automakers. While this upward shift may capture the combined effect of $\Delta G$ and $\Delta c$ due to the regulations, it is a lower bound of the effect of $\Delta G$ as long as the Japanese regulations did not systematically increase the fuel economy cost $(c)$ of the Japanese vehicles in the dataset (i.e., those sold in the US market), conditional on $\mathbf{x}_{\text {imt }}, \delta_{m}$, and $\eta_{t}{ }^{8}$ The regression results in Sect. 4.4 indicate that this condition is likely to hold for them.

\footnotetext{
7 Transmission types are automatic (AT), semi-automatic (SAT), and manual (MT). Drivetrain types are front wheel drive (FWD), rear wheel drive (RWD), and all/four wheel drive (AWD/4WD).

${ }^{8}$ To be more precise, suppose that the true model is

$$
\ln e_{i m t}=\bar{\alpha}_{t} J_{m t}+\bar{\gamma}^{\prime} \mathbf{x}_{i m t}+\bar{\theta} c_{i m t}+\bar{\delta}_{m}+\bar{\eta}_{t}+\bar{\varepsilon}_{i m t},
$$

where $\bar{\theta}>0$ (the term $\bar{\theta} c_{i m t}$ may be replaced with a more general function $g\left(c_{i m t}\right)$ with $d g\left(c_{i m t}\right) / d c_{i m t}>0$ ). Then, $\bar{\alpha}_{t}$ captures technological progress specific only to Japanese firms. Because $c_{i m t}$ is unobservable, I instead estimate Eq. (3) by OLS with $c_{i m t}$ omitted and denote the estimate of $\alpha_{t}$ of Eq. (3) by $\hat{\alpha}_{t}$. Then plim $\hat{\alpha}_{t}=\bar{\alpha}_{t}+\bar{\theta} \lambda_{t}$, where $\lambda_{t}$ is the coefficient of $J_{m t}$ in the regression of $c_{i m t}$ on $J_{m t}, \mathbf{x}_{i m t}$, and manufacturer and year fixed effects (see, e.g., Cameron and Trivedi 2005, p. 93). Therefore, unless $\lambda_{t}$ also shifts upward in the period of the higher regulatory pressure in Japan, the upward shift of $\hat{\alpha}_{t}$ (more precisely, plim $\hat{\alpha}_{t}$ ) during the period is a lower bound of the upward shift of $\bar{\alpha}_{t}$. As an illustration, consider two periods with and without regulatory pressure ( $t=1$ and 0 , respectively), then $\operatorname{plim}\left(\hat{\alpha}_{1}-\hat{\alpha}_{0}\right)=\bar{\alpha}_{1}-\bar{\alpha}_{0}+\bar{\theta}\left(\lambda_{1}-\lambda_{0}\right) \leq \bar{\alpha}_{1}-\bar{\alpha}_{0}$ if $\lambda_{1} \leq \lambda_{0}$.
} 


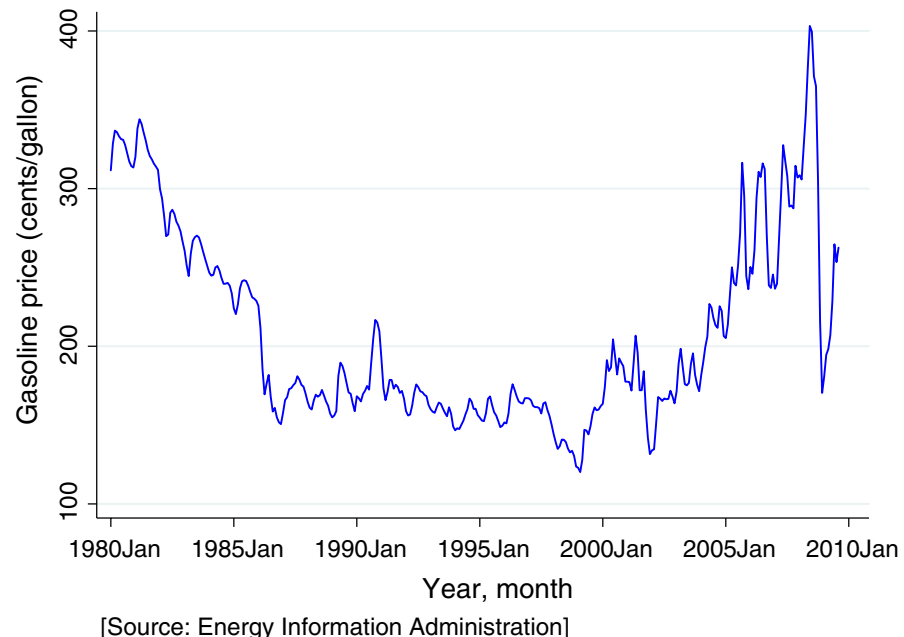

Fig. 5 Regular gasoline prices per gallon in the US (in August 2008 dollars)

As discussed above regarding Fig. 3, vehicle model cycles caused the effect of induced technological change to be observed in the second half of the 1990s, prior to the enforcement of the year 2000 Japanese regulations, making it difficult to clearly determine the "before" and "after" periods. Nevertheless, because the year 2000 targets were announced in January 1993, it is reasonable to assume that the MYs 1985-1993 vehicles were not affected by the regulations (the MY 1993 fleet in the US generally came onto the market in late 1992, prior to the announcement). Thus, in what follows, I will set the pre-treatment period to MYs 1985-1993, which provides a reference point for measuring the impact of the regulations.

The following subsections consider three key issues relating to this strategy. Suppose we observe an upward shift of $\alpha_{t}$ in the data during a period of regulatory pressure. Section 4.3 argues that the tightening of the Japanese regulations is the main cause of such a shift between the mid-1990s and the early 2000s. Section 4.4 examines whether the observed shift results from technological progress $(\Delta G)$, rather than the added production cost $(\Delta c)$. Section 4.5 explains which non-Japanese manufacturers are included in the control group to be compared with their Japanese counterparts.

\subsection{Are the Japanese Regulations the Main Factor?}

After the mid-2000s, oil prices (and motor fuel prices) soared and fuel economy regulations were introduced or tightened in many countries. If a study focuses on this period, it is difficult to identify whether the observed induced technological change, if any, is due to the increased fuel prices or the tightened/introduced regulations in a particular country.

In contrast, from the mid-1980s to the mid-2000s, the period of my analysis, the Japanese fuel economy regulations were very likely the predominant factor in inducing innovations in fuel efficiency. Fuel economy regulations in other countries and world oil prices remained stable in this period. Presented below are observations from three major vehicle markets at that time (Japan, the US, and the EU), which turn out to be the homes of the automakers included in my analysis. Figures 4 and 5 show gasoline prices in Japan 


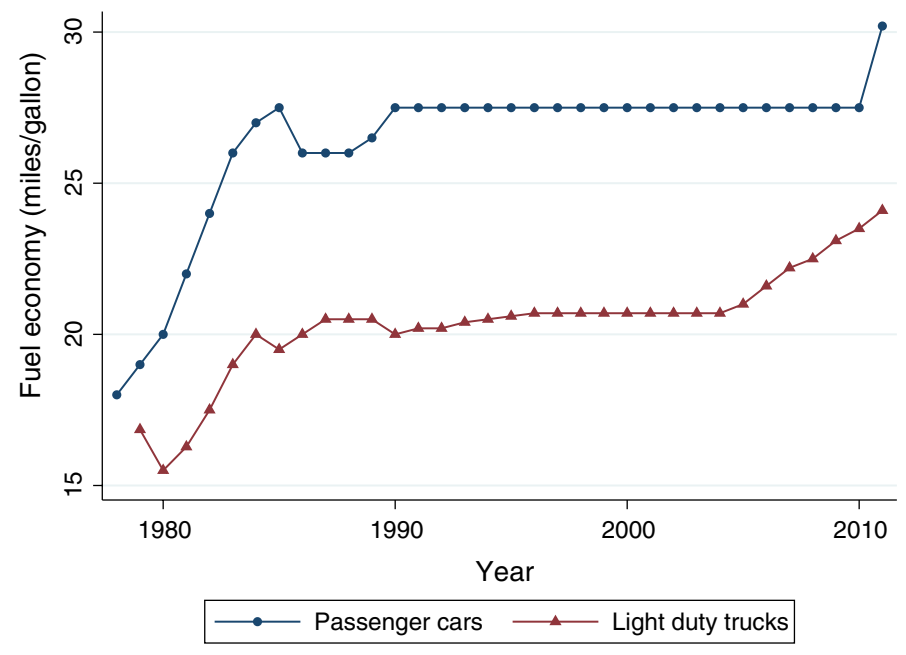

Fig. 6 US CAFE standards

and the US, the two most important markets for the Japanese automakers, where they sell 4.2 million and 2.6 million vehicles, respectively, in 2002, for example. Gasoline prices slowly decreased or remained stable from the mid-1980s until around 2004, implying that consumer demand for fuel economy was also stable in comparison to the period after the mid-2000s. Fuel prices in the EU, another major vehicle market, show similar trends. It is unlikely that fuel prices in this period induced innovations in fuel efficiency technologies.

Moreover, fuel economy regulations were not tightened in the US and the EU during this period. The US CAFE standards remained very stable from the mid-1980s until 2005, when the target mpg for light-duty trucks started to gradually increase (Fig. 6). In the EU, the first fuel economy regulations were adopted only in 2009 to come into effect in 2015, although there were voluntary agreements between carmakers and the European Commission (e.g., the ACEA agreement) that set voluntary targets for 2008 or 2009 (which were not met). It is again unlikely that these markets provided non-negligible regulatory pressure for innovation in vehicle fuel economy before the mid-2000s. These trends in fuel prices and fuel economy regulations suggest that if the Japanese automakers experienced induced technological change between the mid-1990s and the early 2000s, the main driver was the tightening of the Japanese fuel economy regulations during the period.

\subsection{Japanese Vehicles in the US Market}

If a shift of the PPF $(\Delta G)$ is induced by the regulations, a rational automaker would have an incentive to produce all vehicles on the PPF, no matter where they are sold. Then, the effect of the induced shift is also observed in the Japanese automakers' US-market fleet. In reality, the transfer of the effect to their US-market fleet may not be prompt or complete even within a single manufacturer. In this sense, the magnitude of induced technological progress estimated with the US market data shall be considered a lower bound of the actual effect. 
As for the fuel economy cost $(c)$, the Japanese regulations may have increased or decreased the values of $c$ for the Japanese automakers' US-market models through different channels. First, with the stable consumer demand and regulatory requirement for fuel economy in the US (as seen in Sect. 4.3), technological progress $(\Delta G)$ may have resulted in a reduction in $c$ for their US-market models as well as (or instead of) an improvement in $e$ (assuming other attributes are constant). If this is the case, $\hat{\alpha}_{t}$ (the estimate of $\alpha_{t}$ ) obtained from Eq. (3) would underestimate the effect of induced technological change due to the Japanese regulations, providing another reason to interpret $\hat{\alpha}_{t}$ as a lower bound of the actual effect.

Second, if the tightened Japanese regulations increased the fuel economy cost $(c)$ for the Japanese firms' Japanese-market models, these increases might have been incidentally transmitted to their US-market models. This might be the case, for example, if similar models were sold across different markets with little adjustment in their specifications. In the framework of Eq. (3), this leads to an overestimation of the magnitude of induced technological change. The following results, however, indicate that such increases in $c$ were negligible for the Japanese firms' US-market fleet.

Using the US fuel economy test data (as described in Sect. 4.1) for the vehicles manufactured by the Japanese firms in the treatment group (Honda, Isuzu, Mazda, Mitsubishi, Nissan, Subaru, Suzuki, and Toyota) and sold in the US new vehicle market in 2004, I estimate

$$
\ln e_{i m}=\beta D_{i m}+\gamma^{\prime} \mathbf{x}_{i m}+\delta_{m}+\varepsilon_{i m},
$$

where vehicle configuration $i$ is from manufacturer $m$ and the other variables are as defined previously for Eq. (3). The variable of interest here is the indicator variable $D_{i m}$, which equals one if configuration $i$ 's engine size was also available in its manufacturer $m$ 's new vehicle fleet in Japan for the same year 2004, and zero otherwise. ${ }^{9}$ Thus, $D_{i m}$ is a proxy for the similarity of $i$ 's characteristics to those of $m$ 's Japanese-market configurations.

If the increases in the fuel economy cost $(c)$, particularly those in the engine cost, for an automaker's Japanese-market models were transmitted to the same producer's US-market models and improved their fuel economy, I would obtain a positive estimate of $\beta$ in Eq. (5). This is because configuration $i$ with $D_{i m}=1$ is more susceptible to this effect than configuration $j$ with $D_{j m}=0$ due to $i$ 's relative similarity to firm $m$ 's Japanese-market fleet. In column [1] of Table 1, $\beta$ is estimated to be insignificant (both statistically and in magnitude), implying that the Japanese regulations had only negligible effects on the fuel economy cost (c) of the Japanese vehicles offered in the US market.

Column [2] of Table 1 considers an additional condition for $D_{i m}$ : it equals one if (and only if) vehicle configuration $i$ 's engine size was also available in $m$ 's new vehicle fleet in Japan for 2004 (as in column [1]), and configuration $i$ was manufactured in Japan (and exported to the US). Historically, few vehicle models manufactured by Japanese automakers outside of Japan have been commercially exported to the Japanese market, except for a small number of captive import models for which Japan is not a primary market. Therefore, these vehicles would be less affected by the Japanese regulations. The definition of $D_{i m}$ in column [2] takes this aspect into account: the vehicles that are most susceptible to the incidental increases in $c$ would be those similar to Japanese-market models and manufactured in Japan. In column [2], the estimate of $\beta$ is slightly negative and again

\footnotetext{
${ }^{9}$ For the years prior to 2004, this analysis is infeasible due to the lack of detailed data at the vehicle configuration level for the Japanese market.
} 
Table 1 Does the similarity to Japanese market models affect fuel economy?

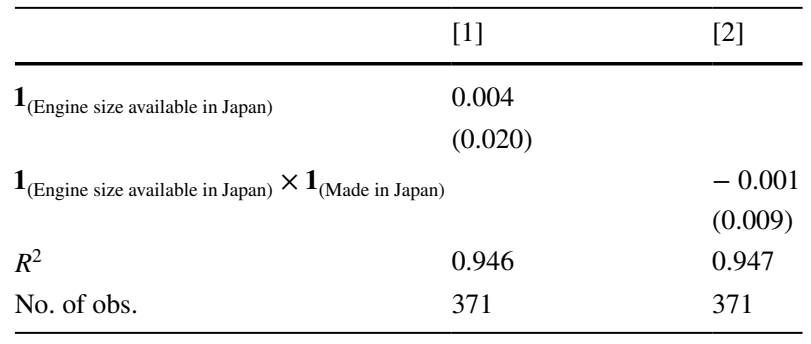

This table reports the estimate of $\beta$ of Eq. (5) for two different definitions of the indicator variable $D_{i m}$ (shown in the left column). Clusterrobust standard errors are in parentheses, where the data are clustered by manufacturer, $m$

$* p<0.1, * * p<0.05, * * * p<0.01$

not statistically different from zero, thus confirming the implication of column [1] that the effects of the Japanese regulations are very limited on the fuel economy cost $(c)$ of the Japanese automakers' US-market models.

\subsection{Non-Japanese Automakers as a Control Group}

I construct a control group from vehicles produced by selected American and European automakers (GM, Ford, Chrysler, BMW, Mercedes, Porsche, and Volvo) and sold in the US. These vehicles serve as a good control group for the following reasons. First, these firms' PPFs were unlikely to be affected by the Japanese fuel economy regulations. Their sales in the Japanese market have been very small relative to those in other markets. For example, in 2001, GM sold only 21,000 vehicles in Japan (all imported), compared to $4,888,000$ vehicles in the US. The other automakers follow similar patterns. It is improbable that their PPFs were affected by the regulations in a market that accounted for only a tiny fraction of their total sales. In addition, between the mid-1980s and the early 2000s, world oil prices were relatively stable and tighter fuel economy regulations were not imposed in the US and the EU (as described in Sect. 4.3). Thus, these non-Japanese firms very likely experienced little, if any, induced innovation in fuel efficiency during this period.

There may possibly be spillover effects among automakers regarding fuel efficiency technologies. If this is the case, innovations by Japanese automakers would have incidental, positive effects on the technology levels of non-Japanese automakers. For this reason (as well as those mentioned above in Sect. 4.4), an estimate of induced technological progress from this framework shall be considered a lower bound of the actual effect.

The non-Japanese automakers in the control group are selected as follows. First, I pick nine non-Japanese firms who constantly participated in the US market between 1985 and 2004 by introducing new configurations in most (i.e., more than 17) of the years in the period (all the Japanese firms in the treatment group satisfy this condition). Then, I exclude two firms (Volkswagen and Hyundai) that were likely to be technologically very different from the Japanese firms during the pre-treatment period 
Table 2 Summary statistics (mean and standard deviation)

\begin{tabular}{|c|c|c|c|c|}
\hline \multirow[t]{2}{*}{ Group } & \multicolumn{2}{|c|}{$\begin{array}{l}\text { Treatment } \\
(N=5353)\end{array}$} & \multicolumn{2}{|c|}{$\begin{array}{l}\text { Control } \\
(N=6223)\end{array}$} \\
\hline & Mean & SD & Mean & $\mathrm{SD}$ \\
\hline Fuel economy (mpg) & 26.9 & 5.5 & 25.4 & 4.7 \\
\hline Engine displacement (cid) & 158 & 50 & 185 & 54 \\
\hline Weight (lb) & 3565 & 696 & 3728 & 699 \\
\hline Horsepower (hp) & 162 & 64 & 166 & 60 \\
\hline Light-duty truck & 0.38 & 0.49 & 0.44 & 0.50 \\
\hline Manual transmission & 0.41 & 0.49 & 0.38 & 0.49 \\
\hline Semi-auto transmission & 0.04 & 0.20 & 0.02 & 0.15 \\
\hline Automatic transmission & 0.55 & 0.50 & 0.59 & 0.49 \\
\hline FWD & 0.45 & 0.50 & 0.40 & 0.49 \\
\hline RWD & 0.24 & 0.43 & 0.40 & 0.49 \\
\hline AWD/4WD & 0.32 & 0.47 & 0.21 & 0.40 \\
\hline
\end{tabular}

The treatment group consists of eight Japanese automakers: Honda, Isuzu, Mazda, Mitsubishi, Nissan, Subaru, Suzuki, and Toyota. The control group consists of seven American and European automakers: Chrysler, Ford, GM, BMW, Mercedes, Porsche, and Volvo

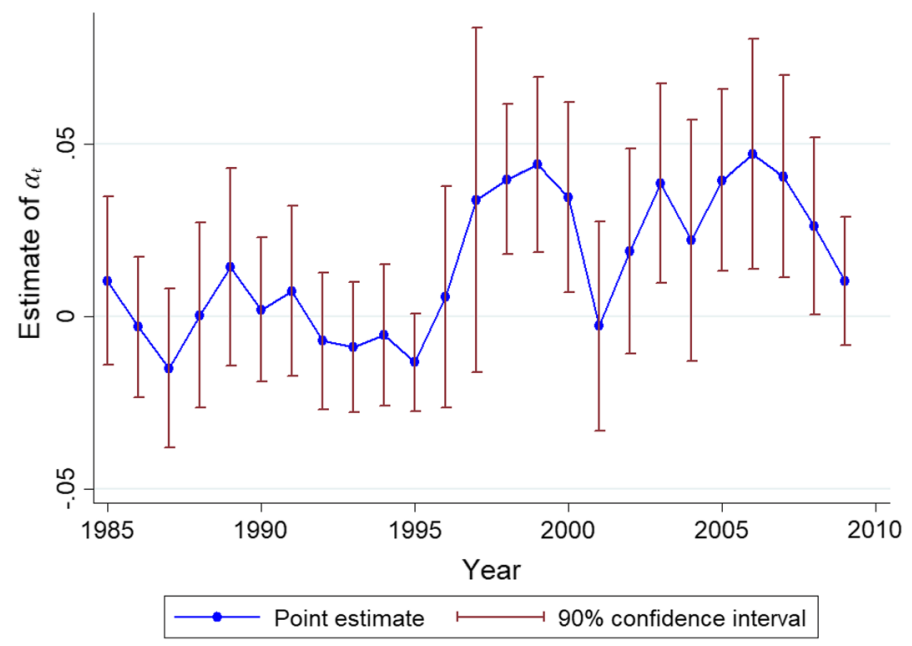

Fig. 7 Relative fuel economy (Japanese relative to non-Japanese vehicles) conditional on other attributes. Note: The estimate of $\alpha_{t}$ of Eq. (3) is plotted for each year. The average of $\alpha_{t}$ over 1985-1993 is normalized to zero 
Table 3 Estimation of the production possibility frontier (1985-2004/2009)

\begin{tabular}{|c|c|c|c|c|c|c|}
\hline & [1] & [2] & [3] & [4] & [5] & [6] \\
\hline$t$ (i.e., time trend) & & & & & $\begin{array}{l}0.007 * * * \\
(0.001)\end{array}$ & $\begin{array}{l}0.007 * * * \\
(0.001)\end{array}$ \\
\hline Japanese $\times t \times \mathbf{1}_{(t \leq 1993)}$ & & $\begin{array}{l}-0.001 \\
(0.003)\end{array}$ & & $\begin{array}{l}0.000 \\
(0.003)\end{array}$ & & \\
\hline $\log ($ Weight $)$ & $\begin{array}{l}3.096 \\
(2.426)\end{array}$ & $\begin{array}{l}3.024 \\
(2.419)\end{array}$ & $\begin{array}{l}3.072 * * \\
(1.187)\end{array}$ & $\begin{array}{l}2.882 * * \\
(1.120)\end{array}$ & $\begin{array}{l}3.988 \\
(2.695)\end{array}$ & $\begin{array}{l}2.968 \\
(2.225)\end{array}$ \\
\hline $\log ($ Horsepower $)$ & $\begin{array}{l}-3.773 * * * \\
(0.568)\end{array}$ & $\begin{array}{l}-3.747 * * * \\
(0.569)\end{array}$ & $\begin{array}{l}-3.517 * * * \\
(0.478)\end{array}$ & $\begin{array}{l}-3.465^{* * *} \\
(0.418)\end{array}$ & $\begin{array}{l}-3.988^{* * *} \\
(0.618)\end{array}$ & $\begin{array}{l}-3.101 * * * \\
(0.599)\end{array}$ \\
\hline $\log ($ Engine $)$ & $\begin{array}{l}-0.021 \\
(0.794)\end{array}$ & $\begin{array}{l}-0.006 \\
(0.785)\end{array}$ & $\begin{array}{l}0.542 \\
(0.746)\end{array}$ & $\begin{array}{l}0.581 \\
(0.752)\end{array}$ & $\begin{array}{l}-0.855 \\
(1.047)\end{array}$ & $\begin{array}{l}0.107 \\
(1.229)\end{array}$ \\
\hline$[\log (\text { Weight })]^{2}$ & $\begin{array}{l}-0.369^{*} \\
(0.187)\end{array}$ & $\begin{array}{l}-0.363^{*} \\
(0.186)\end{array}$ & $\begin{array}{l}-0.294^{* * *} \\
(0.094)\end{array}$ & $\begin{array}{l}-0.280 * * * \\
(0.089)\end{array}$ & $\begin{array}{l}-0.461^{* *} \\
(0.200)\end{array}$ & $\begin{array}{l}-0.265 \\
(0.169)\end{array}$ \\
\hline$[\log (\text { Horsepower })]^{2}$ & $\begin{array}{l}-0.037 \\
(0.040)\end{array}$ & $\begin{array}{l}-0.036 \\
(0.040)\end{array}$ & $\begin{array}{l}0.013 \\
(0.073)\end{array}$ & $\begin{array}{l}0.013 \\
(0.072)\end{array}$ & $\begin{array}{l}-0.019 \\
(0.041)\end{array}$ & $\begin{array}{l}0.051 \\
(0.079)\end{array}$ \\
\hline$[\log (\text { Engine })]^{2}$ & $\begin{array}{l}0.001 \\
(0.057)\end{array}$ & $\begin{array}{l}0.004 \\
(0.058)\end{array}$ & $\begin{array}{l}0.018 \\
(0.123)\end{array}$ & $\begin{array}{l}0.018 \\
(0.128)\end{array}$ & $\begin{array}{l}0.022 \\
(0.063)\end{array}$ & $\begin{array}{l}0.056 \\
(0.154)\end{array}$ \\
\hline $\log ($ Weight $) \times \log ($ Horsepower $)$ & $\begin{array}{l}0.500^{* * * *} \\
(0.089)\end{array}$ & $\begin{array}{l}0.499 * * * \\
(0.088)\end{array}$ & $\begin{array}{l}0.391 * * * \\
(0.106)\end{array}$ & $\begin{array}{l}0.386 * * * \\
(0.098)\end{array}$ & $\begin{array}{l}0.525^{* * *} \\
(0.103)\end{array}$ & $\begin{array}{l}0.304 * \\
(0.142)\end{array}$ \\
\hline $\log ($ Weight $) \times \log ($ Engine $)$ & $\begin{array}{l}-0.015 \\
(0.126)\end{array}$ & $\begin{array}{l}-0.019 \\
(0.128)\end{array}$ & $\begin{array}{l}-0.125 \\
(0.149)\end{array}$ & $\begin{array}{l}-0.128 \\
(0.154)\end{array}$ & $\begin{array}{l}0.081 \\
(0.166)\end{array}$ & $\begin{array}{l}-0.110 \\
(0.222)\end{array}$ \\
\hline $\log ($ Horsepower $) \times \log ($ Engine $)$ & $\begin{array}{l}-0.006 \\
(0.068)\end{array}$ & $\begin{array}{l}-0.009 \\
(0.067)\end{array}$ & $\begin{array}{l}0.017 \\
(0.131)\end{array}$ & $\begin{array}{l}0.015 \\
(0.130)\end{array}$ & $\begin{array}{l}-0.038 \\
(0.058)\end{array}$ & $\begin{array}{l}0.002 \\
(0.087)\end{array}$ \\
\hline Light-duty truck & $\begin{array}{l}-0.052^{* * *} \\
(0.005)\end{array}$ & $\begin{array}{l}-0.052^{* * *} \\
(0.005)\end{array}$ & $\begin{array}{l}-0.052^{* * *} \\
(0.004)\end{array}$ & $\begin{array}{l}-0.052^{* * *} \\
(0.004)\end{array}$ & $\begin{array}{l}-0.054^{* * *} \\
(0.006)\end{array}$ & $\begin{array}{l}-0.057^{* * *} \\
(0.004)\end{array}$ \\
\hline Manual transmission & $\begin{array}{l}0.034 * * * \\
(0.006)\end{array}$ & $\begin{array}{l}0.034 * * * \\
(0.006)\end{array}$ & $\begin{array}{l}0.030 * * * \\
(0.007)\end{array}$ & $\begin{array}{l}0.030 * * * \\
(0.006)\end{array}$ & $\begin{array}{l}0.039 * * * \\
(0.005)\end{array}$ & $\begin{array}{l}0.036^{* * * *} \\
(0.006)\end{array}$ \\
\hline Semi-auto transmission & $\begin{array}{l}0.015 \\
(0.010)\end{array}$ & $\begin{array}{l}0.015 \\
(0.010)\end{array}$ & $\begin{array}{l}0.010 \\
(0.012)\end{array}$ & $\begin{array}{l}0.010 \\
(0.012)\end{array}$ & $\begin{array}{l}-0.011 \\
(0.010)\end{array}$ & $\begin{array}{l}-0.015 \\
(0.010)\end{array}$ \\
\hline RWD & $\begin{array}{l}-0.038 * * * \\
(0.008)\end{array}$ & $\begin{array}{l}-0.037^{* * *} * \\
(0.008)\end{array}$ & $\begin{array}{l}-0.035^{* * *} \\
(0.006)\end{array}$ & $\begin{array}{l}-0.034 * * * \\
(0.006)\end{array}$ & $\begin{array}{l}-0.036^{* * *} \\
(0.010)\end{array}$ & $\begin{array}{l}-0.031^{* * *} \\
(0.007)\end{array}$ \\
\hline AWD/4WD & $\begin{array}{l}-0.066^{* * *} \\
(0.013)\end{array}$ & $\begin{array}{l}-0.066^{* * *} \\
(0.013)\end{array}$ & $\begin{array}{l}-0.070^{* * *} \\
(0.010)\end{array}$ & $\begin{array}{l}-0.070 * * * \\
(0.010)\end{array}$ & $\begin{array}{l}-0.066^{* * *} \\
(0.016)\end{array}$ & $\begin{array}{l}-0.070^{* * *} \\
(0.013)\end{array}$ \\
\hline Firm fixed effects & Yes & Yes & Yes & Yes & Yes & Yes \\
\hline Year fixed effects & Yes & Yes & Yes & Yes & No & No \\
\hline Japanese $\times$ Year fixed effects & Yes & '94-'09 & Yes & '94-'09 & Yes & Yes \\
\hline Smallest and largest included & Yes & Yes & No & No & Yes & No \\
\hline Period & '85-'09 & '85-'09 & '85-'09 & '85-'09 & '85-'04 & '85-'04 \\
\hline$R^{2}$ & 0.893 & 0.893 & 0.858 & 0.858 & 0.890 & 0.854 \\
\hline No. of obs. & 11576 & 11576 & 7945 & 7945 & 9647 & 6584 \\
\hline
\end{tabular}

This table reports the results of estimating Eq. (3): $\ln e_{i m t}=\alpha_{t} J_{m t}+\gamma^{\prime} \mathbf{x}_{i m t}+\delta_{m}+\eta_{t}+\epsilon_{i m t}$. Cluster-robust standard errors are in parentheses, where the data are clustered by manufacturer, $m$

$* p<0.1, * * p<0.05, * * * p<0.01$ 
(1985-1993). ${ }^{10}$ This leaves seven American and European automakers (GM, Ford, Chrysler, BMW, Mercedes, Porsche, and Volvo).

To enhance the comparability of the treatment and control groups, the sample used in the following analysis excludes those vehicles in the treatment (control) group in year $t$ that weigh more than the maximum weight or less than the minimum weight of the vehicles in the control (treatment, respectively) group in the same year. The same process is repeated with engine displacement and horsepower sequentially replacing weight, thereby removing those observations that do not have comparable configurations in the other group. Table 2 reports the summary statistics (mean and standard deviation) for the sample thus constructed, which is used in the baseline estimation of Eq. (3) for MYs 1985-2009 (to be reported in Table 3 and Fig. 7 below).

\section{Estimation Results}

\subsection{Analysis of the Overall Trend (1985-2009)}

First, I estimate Eq. (3) and graphically analyze the overall trend of induced innovation in fuel efficiency without assuming a specific treatment period. I want to confirm that in the pre-treatment period (1985-1993), the Japanese and non-Japanese firms have similar trends with respect to fuel efficiency, conditional on other vehicle attributes. I also want to see whether the relative fuel efficiency of the treatment group responds to the increased regulatory pressure in Japan after the mid-1990s.

The coefficients of primary interest are $\alpha_{t}$ 's. The average of $\alpha_{t}$ 's for 1985-1993 is normalized to zero, so that $\alpha_{t}$ can be interpreted as follows. Suppose that two hypothetical vehicle models (model 1 from Japanese automaker $A$ and model 2 from non-Japanese automaker $B$ ) with the same non-fuel-economy attributes $(\mathbf{x})$ are produced on the PPF of the respective firms each year (so that the error term $\varepsilon_{i m t}=0$ ). Then, $\ln e_{1 A t}-\ln e_{2 B t}=\alpha_{t}+\delta_{A}-\delta_{B}$, which is approximately the relative difference in fuel economy (mpg) between models 1 and 2 in year $t\left(=\frac{e_{1 A t}-e_{2 B t}}{e_{2 B t}}\right)$. As $\sum_{s=1985}^{1993} \alpha_{s}=0$ by construction, $\alpha_{t}$ is approximately equal to $\frac{e_{1 A t}}{e_{2 B t}}-\frac{1}{9} \sum_{s=1985}^{1993} \frac{e_{1 A s}}{e_{2 B s}}$, or the change in relative fuel economy $\left(\frac{e_{1 A t}}{e_{2 B t}}\right)$ from the pre-treatment period average.

Based on the estimation of Eq. (3), Fig. 7 plots $\hat{\alpha}_{t}$ (the estimate of $\alpha_{t}$ ) for the period of 1985-2009, with standard errors clustered at the manufacturer $(m)$ level. Figure 7 shows that $\hat{\alpha}_{t}$ is stable until the mid-1990s, suggesting that the Japanese and non-Japanese firms have comparable pre-treatment trends in fuel economy, conditional on $\mathbf{x}_{i m t}$ and $\delta_{m}$. The estimates of $\gamma$, though not of primary interest here, are reported in column [1] of Table 3.

Column [2] of Table 3 also confirms this point. In column [2], the variable $J_{m} \times t \times \mathbf{1}_{(t \leq 1993)}$ (i.e., Japanese $\times t \times \mathbf{1}_{(t \leq 1993)}$ in the table) replaces column [1]'s $J_{m t}$ (i.e., Japanese $\times$ Year fixed effects in the table) for the pre-treatment period (1985 $\leq t \leq 1993)$,

\footnotetext{
${ }^{10}$ More specifically, using the MYs 1985-1993 vehicles from the Japanese firms in the treatment group and the nine non-Japanese firms, I estimate

$$
\ln e_{i m t}=\gamma^{\prime} \mathbf{x}_{i m t}+\delta_{m}+\eta_{t}+\varepsilon_{i m}
$$

I compare the estimated manufacturer fixed effects, and include a non-Japanese firm in the control group unless its fuel efficiency conditional on $\mathbf{x}_{i m t}$ and year fixed effects is significantly different (at the 5\% level) from every Japanese firm's.
} 


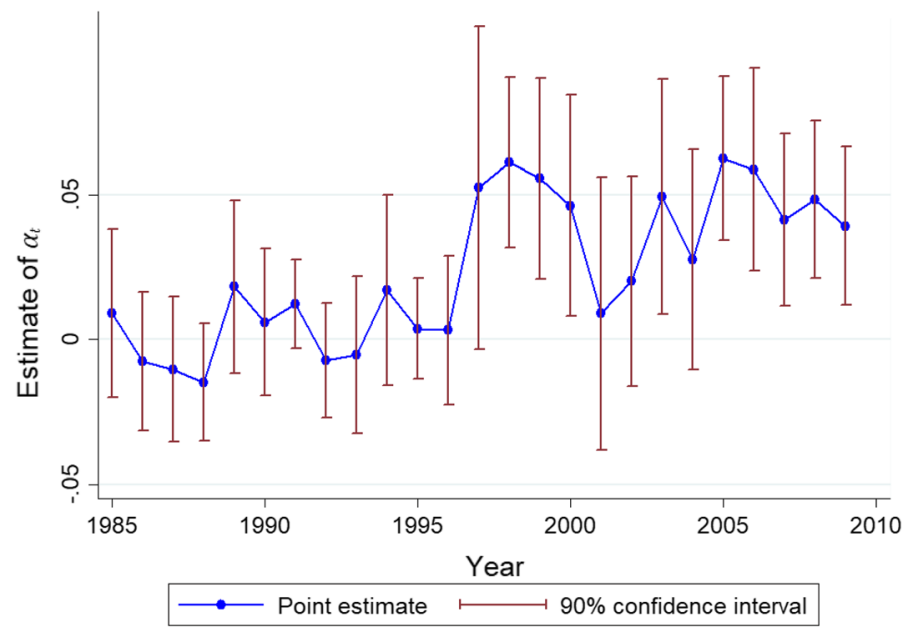

Fig. 8 Relative fuel economy (Japanese relative to non-Japanese vehicles) conditional on other attributes, with the smallest and largest vehicles excluded from the sample. Note: The estimate of $\alpha_{t}$ of Eq. (3) is plotted for each year. The average of $\alpha_{t}$ over 1985-1993 is normalized to zero

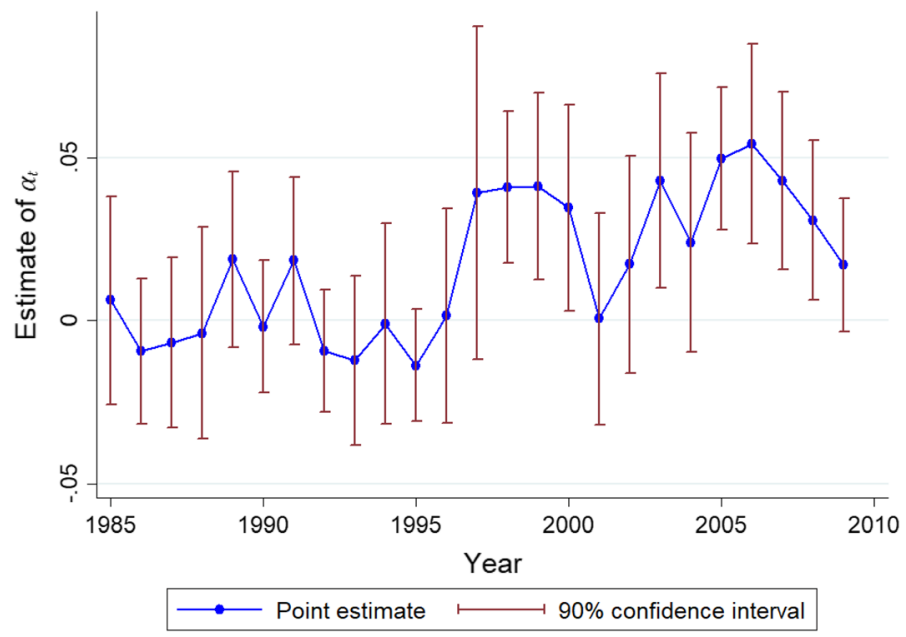

Fig. 9 Relative fuel economy (Japanese relative to non-Japanese vehicles) conditional on other attributes, with the largest vehicles excluded from the sample. Note: The estimate of $\alpha_{t}$ of Eq. (3) is plotted for each year. The average of $\alpha_{t}$ over 1985-1993 is normalized to zero

thus parametrically measuring the time trend applicable only to the pre-treatment Japanese vehicles. The (economically and statistically) insignificant coefficient estimate (- 0.001) for this variable, $J_{m} \times t \times \mathbf{1}_{(t \leq 1993)}$, indicates that conditional on $\mathbf{x}_{i m t}$ and $\delta_{m}$, both groups exhibit very similar time trends in fuel economy during 1985-1993, which are captured by year fixed effects $\left(\eta_{t}\right)$.

Figure 8 and column [3] (or [4]) check the robustness of this finding by repeating the estimation of Eq. (3) with dropping the smallest and largest vehicles in the original 
sample, potential outliers that may be driving the above results. ${ }^{11}$ This truncated sample gives much the same results as the original sample (Fig. 7 and columns [1] and [2]).

With these results, both the Japanese and non-Japanese vehicles (manufacturers) are reasonably assumed to have followed a common time trend during 1985-1993 with respect to the effect of $\Delta G$ and $\Delta c$ on fuel economy. Then, as argued in Sect. 4.3, had it not been for the tightening of the Japanese fuel economy targets, both groups would have continued to have a common trend even after the pre-treatment period. The non-Japanese vehicles then serve as a good control group, and the trend in $\alpha_{t}$ after the mid-1990s can be attributed to the tightened Japanese regulations.

Figures 7 and 8 both exhibit a trend change around 1996-1997, and since then, $\hat{\alpha}_{t}$ mostly remains much higher than before. ${ }^{12}$ This is consistent with Fig. 3, which shows a rapid fuel economy improvement in the Japanese market (conditional on weight class) starting around 1995-1997. The trend change in Figs. 7 and 8 thus signifies the impact of the tightened Japanese regulations as observed in the Japanese vehicles in the US market. Furthermore, with the results in Table 1, which suggest only negligible effects of the Japanese regulations on the fuel economy cost $(c)$ of the US-market models, the upward shift in Figs. 7 and 8 after the second half of the 1990s is interpreted as the technological progress $(\Delta G)$ induced by the Japanese regulations.

Interestingly, Fig. 7 also displays a sharp decline in the final few years (and so does Fig. 8 to a lesser extent). This results from substantial improvements in fuel economy (conditional on $\mathbf{x}_{i m t}$ and $\delta_{m}$ ) in the late 2000 s achieved by the non-Japanese firms. In particular, improvements in their small cars matter as shown in Fig. 9, which excludes the largest vehicles from the original sample (as in Fig. 8) but not the smallest ones and thus reflects improvements in the latter. As discussed above, these firms had been under little pressure to improve fuel economy from the mid-1980s until the oil (fuel) price hikes (which led to stronger consumer demand for fuel economy) and the gradual tightening of the US or EU fuel economy standards in the mid-2000s. Facing the changes in the mid-2000s, these manufacturers presumably became more focused on the fuel economy of their vehicles, especially of their small cars that can naturally achieve better mpg ratings than large vehicles. It appears that their effort began to materialize as substantial fuel economy improvements (conditional on $\mathbf{x}_{i m t}$ and $\delta_{m}$ ) in the late 2000s. On the other hand, it is likely that the Japanese firms, which had already been under regulatory pressure for fuel economy improvement in their home market (Japan), were less affected by the oil price hikes or the tightened US or EU regulations. Thus, the decline in the final years of Figs. 7, 8 and 9 is consistent with my identification strategy that only Japanese automakers went through induced innovations in fuel efficiency from the mid-1990s to the mid-2000s.

Finally, columns [5] and [6] of Table 3 present the estimation results for 1985-2004, with year fixed effects replaced by a linear time trend. Note that this period precedes the oil price hikes and tighter US and EU fuel economy regulations, so that the non-Japanese automakers in the control group were under little pressure to achieve better fuel economy.

\footnotetext{
11 Relatively speaking, the distribution of vehicles in the treatment (control) group is skewed toward small (large) vehicles. I thus remove the lightest $10 \%$ and the heaviest $10 \%$ of the year $t$ vehicles in the original sample of columns [1] and [2]. The same procedure is repeated sequentially for horsepower and engine size. 12 In both figures (as well as in Fig. 9 below), the years 2000 and 2001 show relatively low estimates for the period after the late 1990s. This could be explained by, for example, spillover effects from Japanese to non-Japanese automakers, or just random shocks due to different vehicle model cycles across the automakers. With the limited information available, it is difficult to further explore this point.
} 
The time trend captures the effects of factors such as autonomous technological progress and temporal changes in $c$. As discussed above, both the Japanese and non-Japanese firms are reasonably assumed to have followed a common trend with respect to these factors. This common, autonomous rate of fuel economy improvement (conditional on other explanatory variables) is estimated at $0.7 \%$ annually.

\subsection{Direct Comparison of the Pre-treatment and Treatment Periods}

Based on the findings from Figs. 7, 8 and 9, I now consider a specific treatment period, and directly compare it with the pre-treatment period. Using the vehicle specification data for the pre-treatment period MYs 1985-1993 and the treatment period MYs $T_{0}-T_{1}$ (to be defined below), I estimate

$$
\ln e_{i m t}=\alpha J_{m} \cdot \mathbf{1}_{\left(T_{0} \leq t \leq T_{1}\right)}+\gamma^{\prime} \mathbf{x}_{i m t}+\delta_{m}+\eta_{t}+\varepsilon_{i m t},
$$

where $J_{m} \cdot \mathbf{1}_{\left(T_{0} \leq t \leq T_{1}\right)}$ is a dummy variable that equals one for the Japanese vehicles during MYs $T_{0}-T_{1}$ when the regulatory pressure from the fuel economy regulations in Japan affected its automakers. This period is compared with MYs 1985-1993. ${ }^{13}$ The coefficient of interest is $\alpha$, which measures the change in fuel economy that is specific to the Japanese vehicles in the treatment period, conditional on other vehicle attributes $\mathbf{x}_{i m t}$ and manufacturer and year fixed effects. As discussed previously, $\alpha$ is interpreted as a lower bound of the effect of technological progress induced by the Japanese regulations.

Regarding the treatment period, vehicle model cycles, as discussed before, caused the impact of induced innovation to appear in the second half of the 1990s, prior to the enforcement year of 2000 (Figs. 7, 8, 9), making it difficult to clearly determine the beginning of the treatment period $\left(T_{0}\right)$. Thus, I report the results for different values of $T_{0}(1995$, 1996, 1997, and 1998).

I also consider different choices for the end of the treatment period $\left(T_{1}\right)$. First, I set a shorter treatment period with $T_{1}=2000$ or 2001, assuming that the Japanese producers had been under regulatory pressure (at least) until the target enforcement year of $2000 .{ }^{14}$ Columns [1], [2], [4], and [5] of Table 4 report $\hat{\alpha}$ (the estimate of $\alpha$ ) for different treatment periods ending in either MY 2000 or 2001. Columns [1] and [2] are based on the sample with the smallest and largest vehicles included (sample 1), as in columns [1], [2], and [5] of Table 3, while columns [4] and [5] use the sample excluding those vehicles (sample 2), as in columns [3], [4], and [6] of Table 3. The regression results demonstrate a sizeable effect of induced technological progress. In most cases, $\hat{\alpha}$ is approximately $0.03-0.05$ and is statistically significant. Sample 2 gives higher estimates than sample 1 (though not statistically significantly). The estimates indicate that the Japanese regulations induced at least a 3-5\% improvement in the PPF for fuel efficiency, aside from autonomous technological change. Compared with the autonomous improvement rate of $0.7 \%$ per annum (columns [5] and [6] of Table 3), the estimated effect of this induced innovation is at least as large as the improvement that would have occurred over 4-7 years with no pressure from fuel prices or fuel economy regulations.

\footnotetext{
${ }^{13}$ Figures 3 and 7 indicate little to no sign of induced innovation until around 1995. Setting the end of the pre-treatment period to 1994 or 1995 yields essentially the same results as below.

14 The target enforcement year here refers to April 2000-March 2001, Japan's fiscal year 2000. Thus, I consider the MY 2001 vehicles in the US, which came onto the market in late (calendar year) 2000, as well as the MY 2000 vehicles.
} 
Table 4 Estimated lower bounds of the effect of induced technological progress

\begin{tabular}{|c|c|c|c|c|c|c|}
\hline \multirow[t]{2}{*}{ Sample } & \multicolumn{3}{|c|}{ Sample 1} & \multicolumn{3}{|l|}{ Sample 2} \\
\hline & [1] & [2] & [3] & {$[4]$} & [5] & [6] \\
\hline To & 2000 & 2001 & 2004 & 2000 & 2001 & 2004 \\
\hline \multicolumn{7}{|l|}{ From } \\
\hline 1995 & $\begin{array}{l}0.023 \\
(0.013)\end{array}$ & $\begin{array}{l}0.021 \\
(0.013)\end{array}$ & $\begin{array}{l}0.023^{*} \\
(0.013)\end{array}$ & $\begin{array}{l}0.035^{*} \\
(0.017)\end{array}$ & $\begin{array}{l}0.033^{*} \\
(0.018)\end{array}$ & $\begin{array}{l}0.033^{*} \\
(0.018)\end{array}$ \\
\hline 1996 & $\begin{array}{l}0.031^{*} \\
(0.015)\end{array}$ & $\begin{array}{l}0.028^{*} \\
(0.016)\end{array}$ & $\begin{array}{l}0.029^{*} \\
(0.014)\end{array}$ & $\begin{array}{l}0.041 * * \\
(0.019)\end{array}$ & $\begin{array}{l}0.038^{*} \\
(0.021)\end{array}$ & $\begin{array}{l}0.037^{*} \\
(0.019)\end{array}$ \\
\hline 1997 & $\begin{array}{l}0.040^{* * *} \\
(0.016)\end{array}$ & $\begin{array}{l}0.033^{*} \\
(0.016)\end{array}$ & $\begin{array}{l}0.032^{* *} \\
(0.014)\end{array}$ & $\begin{array}{l}0.055^{* *} \\
(0.022)\end{array}$ & $\begin{array}{l}0.048^{*} \\
(0.024)\end{array}$ & $\begin{array}{l}0.043^{*} \\
(0.021)\end{array}$ \\
\hline 1998 & $\begin{array}{l}0.039 * * \\
(0.013)\end{array}$ & $\begin{array}{l}0.029 * \\
(0.014)\end{array}$ & $\begin{array}{l}0.030 \text { ** } \\
(0.013)\end{array}$ & $\begin{array}{l}0.052 * * \\
(0.019)\end{array}$ & $\begin{array}{l}0.044^{*} \\
(0.022)\end{array}$ & $\begin{array}{l}0.038^{*} \\
(0.019)\end{array}$ \\
\hline
\end{tabular}

For different treatment periods and samples, this table reports the estimate of $\alpha$ of Eq. (7): $\ln e_{i m t}=\alpha J_{m} \cdot \mathbf{1}_{\left(T_{0} \leq t \leq T_{1}\right)}+\gamma^{\prime} \mathbf{x}_{i m t}+\delta_{m}+\eta_{t}+\epsilon_{i m t}$. The smallest and largest vehicles are included (excluded) in sample 1 (sample 2). Cluster-robust standard errors are in parentheses, where the data are clustered by manufacturer, $m$

${ }^{*} p<0.1, * * p<0.05, * * * p<0.01$

Second, $T_{1}$ is set at MY 2004. This means that the 2010 Japanese targets (set in 1999 to be enforced in 2010) kept the Japanese automakers under regulatory pressure even after 2000. Indeed, they reacted to the 2010 targets quickly, and the average new vehicle in each weight class met the corresponding target by 2005 at the latest, implying that the 2000 and 2010 regulations continuously pressured automakers to improve fuel economy both before and after 2000. As described above, fuel (oil) prices were relatively stable until the end of 2003 (Figs. 4 and 5), and the US CAFE standards began to be gradually tightened only after MY 2005 (Fig. 6). Thus, the effect of induced innovation can be reasonably assumed to have been negligible for the non-Japanese vehicles until MY 2004, ${ }^{15}$ while it may have substantially increased after MY 2005 (especially in the late 2000s, as implied by Figs. 7, 8 and 9. Under these circumstances, MY 2004 is selected as the end of the treatment period during which only the Japanese manufacturers were subject to induced technological progress. Columns [3] and [6] of Table 4 show $\hat{\alpha}$ for different treatment periods ending in MY 2004: on the whole, $\hat{\alpha}$ is approximately $0.03-0.04$ and is statistically significant, which is essentially in line with the above result with $T_{1}=2000$ or 2001.

Tables 5 and 6 also compare the two groups of vehicles based on the estimation of Eq. (7), but they distinguish the Japanese vehicles by the location of production. That is, by interacting $J_{m} \cdot \mathbf{1}_{\left(T_{0} \leq t \leq T_{1}\right)}$ with production location dummy variables, I estimate $\alpha$ 's separately in one regression for the Japanese vehicles produced in different locations. Tables 5 and 6 present $\alpha$ 's separately for the Japanese vehicle configurations manufactured only in Japan and exported to the US ("JP" columns) and those manufactured only in North America (Canada, the US, and Mexico) and sold there ("NA" columns). Table 5 (Table 6) uses sample 1 (sample 2) that includes (excludes) the smallest and largest vehicles. The tables show that the effect of induced innovation is much the same in magnitude across the two

${ }^{15}$ MY 2004 vehicles typically came onto the market in late (calendar year) 2003. 
Table 5 Estimated lower bounds by production location (sample 1)

\begin{tabular}{|c|c|c|c|c|c|c|}
\hline \multirow{2}{*}{$\begin{array}{l}\text { To } \\
\text { Made in }\end{array}$} & \multicolumn{2}{|l|}{2000} & \multicolumn{2}{|l|}{2001} & \multicolumn{2}{|l|}{2004} \\
\hline & JP & NA & JP & NA & JP & NA \\
\hline \multicolumn{7}{|l|}{ From } \\
\hline 1995 & $\begin{array}{l}0.016 \\
(0.013)\end{array}$ & $\begin{array}{l}0.020 \\
(0.013)\end{array}$ & $\begin{array}{l}0.015 \\
(0.012)\end{array}$ & $\begin{array}{l}0.017 \\
(0.014)\end{array}$ & $\begin{array}{l}0.018 * \\
(0.010)\end{array}$ & $\begin{array}{l}0.019 \\
(0.015)\end{array}$ \\
\hline 1996 & $\begin{array}{l}0.024 \\
(0.014)\end{array}$ & $\begin{array}{l}0.028 * \\
(0.015)\end{array}$ & $\begin{array}{l}0.022 \\
(0.014)\end{array}$ & $\begin{array}{l}0.023 \\
(0.016)\end{array}$ & $\begin{array}{l}0.024 * * \\
(0.011)\end{array}$ & $\begin{array}{l}0.024 \\
(0.016)\end{array}$ \\
\hline 1997 & $\begin{array}{l}0.037 * * \\
(0.016)\end{array}$ & $\begin{array}{l}0.037 * * \\
(0.016)\end{array}$ & $\begin{array}{l}0.032 * \\
(0.016)\end{array}$ & $\begin{array}{l}0.028 \\
(0.017)\end{array}$ & $\begin{array}{l}0.031 * * \\
(0.012)\end{array}$ & $\begin{array}{l}0.028 \\
(0.017)\end{array}$ \\
\hline 1998 & $\begin{array}{l}0.040 * * \\
(0.015)\end{array}$ & $\begin{array}{l}0.035^{* *} \\
(0.015)\end{array}$ & $\begin{array}{l}0.032 * \\
(0.016)\end{array}$ & $\begin{array}{l}0.024 \\
(0.017)\end{array}$ & $\begin{array}{l}0.031 * * \\
(0.011)\end{array}$ & $\begin{array}{l}0.025 \\
(0.017)\end{array}$ \\
\hline
\end{tabular}

Using sample 1, this table reports the estimate of $\alpha$ of Eq. (7) for different treatment periods and production locations: $\ln e_{i m t}=\sum_{L} \alpha_{L} J_{m} \cdot \mathbf{1}_{\left(T_{0} \leq t \leq T_{1}\right)} \cdot \mathbf{1}_{\left(l_{i m t}=L\right)}+\gamma^{\prime} \mathbf{x}_{i m t}+\delta_{m}+\eta_{t}+\epsilon_{i m t}$, where $l_{\text {imt }}$ represents vehicle configuration imt's production location. The "JP" ("NA") columns show $\hat{\alpha}_{L}$ for $L=$ "Japan only" ("North America only"), i.e., Japanese vehicle configurations in the US market that are manufactured only in Japan (North America). Cluster-robust standard errors are in parentheses, where the data are clustered by manufacturer, $m$

$* p<0.1, * * p<0.05, * * * p<0.01$

production locations. This finding is in line with Table 1 in Sect. 4.4, which also reports that the effect of production locations on fuel economy, conditional on other explanatory variables, is very limited.

Finally, in Table 7, I estimate Eq. (7) with sample 1 again, as in columns [1]-[3] of Table 4, but this time with swapping the roles of fuel economy $\left(e_{i m t}\right)$ and any of the three (non-binary) variables of $\mathbf{x}_{i m t}$ (weight, horsepower, and engine displacement) in the original version of Eq. (7). For example, (the log of) engine displacement serves as the dependent variable, while (the log of) fuel economy enters the right-hand side along with its square and interactions with (the log of) weight and horsepower. The rationale for the swap is that an outward shift of the PPF due to technological progress (as in Fig. 1) is not only regarded as a better fuel economy conditional on other attributes, as originally examined by Eq. (7), but also as, for example, a larger engine displacement conditional on other attributes (including fuel economy). The latter view places weight, horsepower, or engine displacement on the left-hand side of Eq. (7), and fuel economy on the right-hand side. Note, however, that fuel economy is the natural choice for the dependent variable and thus the original specification with fuel economy on the left-hand side is more preferred. This is because the fuel economy tests under the CAFE standards, the source of my dataset, measure and determine the fuel economy of a vehicle that is equipped with a fixed set of (non-fuel-economy) attributes by driving it on a dynamometer, and each test is subject to random noise that is included in the measured fuel economy. Table 7 reports $\hat{\alpha}$ for each dependent variable. The estimates are statistically significant (insignificant) and relatively large (small) when engine displacement (weight or horsepower) is the dependent 
Table 6 Estimated lower bounds by production location (sample 2)

\begin{tabular}{|c|c|c|c|c|c|c|}
\hline \multirow{2}{*}{$\begin{array}{l}\text { To } \\
\text { Made in }\end{array}$} & \multicolumn{2}{|l|}{2000} & \multicolumn{2}{|l|}{2001} & \multicolumn{2}{|l|}{2004} \\
\hline & JP & NA & JP & NA & JP & NA \\
\hline \multicolumn{7}{|l|}{ From } \\
\hline 1995 & $\begin{array}{l}0.028 * \\
(0.016)\end{array}$ & $\begin{array}{l}0.033 * * \\
(0.014)\end{array}$ & $\begin{array}{l}0.027 \\
(0.018)\end{array}$ & $\begin{array}{l}0.032 * \\
(0.017)\end{array}$ & $\begin{array}{l}0.027 * \\
(0.015)\end{array}$ & $\begin{array}{l}0.031 * \\
(0.017)\end{array}$ \\
\hline 1996 & $\begin{array}{l}0.033 * \\
(0.017)\end{array}$ & $\begin{array}{l}0.039 * * \\
(0.017)\end{array}$ & $\begin{array}{l}0.032 \\
(0.019)\end{array}$ & $\begin{array}{l}0.036^{*} \\
(0.019)\end{array}$ & $\begin{array}{l}0.031 * \\
(0.016)\end{array}$ & $\begin{array}{l}0.034^{*} \\
(0.019)\end{array}$ \\
\hline 1997 & $\begin{array}{l}0.050 * * \\
(0.022)\end{array}$ & $\begin{array}{l}0.053 * * \\
(0.020)\end{array}$ & $\begin{array}{l}0.044 * \\
(0.024)\end{array}$ & $\begin{array}{l}0.046^{*} \\
(0.022)\end{array}$ & $\begin{array}{l}0.039 * \\
(0.019)\end{array}$ & $\begin{array}{l}0.041 * \\
(0.021)\end{array}$ \\
\hline 1998 & $\begin{array}{l}0.053 * * \\
(0.021)\end{array}$ & $\begin{array}{l}0.050 * * \\
(0.019)\end{array}$ & $\begin{array}{l}0.043 * \\
(0.024)\end{array}$ & $\begin{array}{l}0.041 * \\
(0.023)\end{array}$ & $\begin{array}{l}0.037 * \\
(0.018)\end{array}$ & $\begin{array}{l}0.036 \\
(0.021)\end{array}$ \\
\hline
\end{tabular}

This table reports the results of using sample 2 to estimate the same model as in Table 5

$* p<0.1, * * p<0.05, * * * p<0.01$

Table 7 Other attributes as the dependent variable

\begin{tabular}{|c|c|c|c|c|c|c|c|c|c|}
\hline \multirow{2}{*}{$\begin{array}{l}\text { Dep. var. } \\
\text { To }\end{array}$} & \multicolumn{3}{|c|}{$\ln ($ Weight $)$} & \multicolumn{3}{|c|}{$\ln ($ Horsepower $)$} & \multicolumn{3}{|l|}{$\ln ($ Engine $)$} \\
\hline & 2000 & 2001 & 2004 & 2000 & 2001 & 2004 & 2000 & 2001 & 2004 \\
\hline \multicolumn{10}{|l|}{ From } \\
\hline 1995 & $\begin{array}{l}-0.004 \\
(0.010)\end{array}$ & $\begin{array}{l}-0.003 \\
(0.010)\end{array}$ & $\begin{array}{l}-0.005 \\
(0.008)\end{array}$ & $\begin{array}{l}-0.007 \\
(0.034)\end{array}$ & $\begin{array}{l}-0.009 \\
(0.030)\end{array}$ & $\begin{array}{l}-0.016 \\
(0.030)\end{array}$ & $\begin{array}{l}0.050^{* *} \\
(0.021)\end{array}$ & $\begin{array}{l}0.048 * * \\
(0.020)\end{array}$ & $\begin{array}{l}0.064 * * * \\
(0.018)\end{array}$ \\
\hline 1996 & $\begin{array}{l}0.001 \\
(0.010)\end{array}$ & $\begin{array}{l}0.001 \\
(0.010)\end{array}$ & $\begin{array}{l}-0.003 \\
(0.008)\end{array}$ & $\begin{array}{l}-0.012 \\
(0.037)\end{array}$ & $\begin{array}{l}-0.014 \\
(0.032)\end{array}$ & $\begin{array}{l}-0.022 \\
(0.032)\end{array}$ & $\begin{array}{l}0.057 * * \\
(0.021)\end{array}$ & $\begin{array}{l}0.054 * * \\
(0.020)\end{array}$ & $\begin{array}{l}0.072^{* * *} \\
(0.018)\end{array}$ \\
\hline 1997 & $\begin{array}{l}0.003 \\
(0.010)\end{array}$ & $\begin{array}{l}0.002 \\
(0.009)\end{array}$ & $\begin{array}{l}-0.003 \\
(0.008)\end{array}$ & $\begin{array}{l}-0.006 \\
(0.043)\end{array}$ & $\begin{array}{l}-0.009 \\
(0.036)\end{array}$ & $\begin{array}{l}-0.020 \\
(0.034)\end{array}$ & $\begin{array}{l}0.073 * * * \\
(0.019)\end{array}$ & $\begin{array}{l}0.066^{* * *} \\
(0.018)\end{array}$ & $\begin{array}{l}0.084 * * * \\
(0.017)\end{array}$ \\
\hline 1998 & $\begin{array}{l}0.008 \\
(0.011)\end{array}$ & $\begin{array}{l}0.005 \\
(0.010)\end{array}$ & $\begin{array}{l}-0.002 \\
(0.008)\end{array}$ & $\begin{array}{l}-0.008 \\
(0.045)\end{array}$ & $\begin{array}{l}-0.012 \\
(0.036)\end{array}$ & $\begin{array}{l}-0.022 \\
(0.034)\end{array}$ & $\begin{array}{l}0.072 * * * \\
(0.021)\end{array}$ & $\begin{array}{l}0.063 * * * \\
(0.020)\end{array}$ & $\begin{array}{l}0.084 * * * \\
(0.018)\end{array}$ \\
\hline
\end{tabular}

This table estimates Eq. (7) as in columns [1]-[3] of Table 4 after swapping the roles of fuel economy and any of the three vehicle attributes (weight, horsepower, and engine displacement) in the original version of Eq. (7). Cluster-robust standard errors are in parentheses, where the data are clustered by manufacturer, $m$

$* p<0.1, * * p<0.05, * * * p<0.01$

variable. ${ }^{16}$ This implies that the technological progress induced by the Japanese regulations mainly helped enhance either the fuel economy or engine displacement of Japanese vehicles in the US market. The large estimates observed when engine displacement is the dependent variable may be because the Japanese vehicles in the dataset tended to carry smaller engines than the American and European vehicles, as suggested in Table 2, making a quick catch-up relatively easy.

\footnotetext{
${ }^{16}$ Using sample 2 and/or additionally considering production locations in the same way as in Tables 5 and 6 leads to very similar findings as in Table 7.
} 


\section{Conclusion}

Given the importance of environmental and energy-efficient technologies for lowering the long-term costs of environmental protection, understanding how environmental policies affect the progress in these technologies is key to effectively designing these policies. I have examined this issue in the context of automobile fuel economy, an important determinant of global carbon emissions, by focusing on the past experiences of Japanese automakers. Fuel economy regulations in Japan started to be tightened in the 1990s. I have analyzed whether the tightened regulations induced technological progress by looking at changes in the characteristics of vehicles produced by Japanese automakers between the 1980s and the 2000s.

In the previous literature, induced innovation in environmental or energy-efficient technologies has been typically measured by changes in relevant patent activities over time. This paper, on the other hand, estimates it by analyzing temporal changes in vehicle characteristics (e.g., fuel economy, weight, and horsepower) that were actually offered in the market. Thus, I aim to fill the gap in the literature between invention (patents) and commercialization (marketed products' characteristics).

The empirical strategy of the paper is to exploit the international differences in fuel economy regulations and the variation across automakers in the relative importance of different national markets in their sales, as in Popp (2006) and Aghion et al. (2016). Japan tightened its fuel economy regulations in the 1990s, preceding other regions such as the US and the EU. Moreover, the Japanese market has accounted for only a small fraction of the total sales of each non-Japanese automaker considered. Under these circumstances, I apply a difference-in-differences regression framework to a vehicle specification dataset from the US market and compare Japanese vehicles with selected American and European vehicles. Focusing on the US market rather than the Japanese market makes it possible to observe the effect of induced technological change without being confounded by the production cost increases that the tightened regulations presumably caused for the Japanese-market models. In addition, the comparison with the control group (the US-market fleet of selected American and European automakers that were unlikely to be affected by the Japanese regulations) "differences out" the factors that are common to both the treatment and control groups, such as autonomous technological change.

The regression analyses reveal sizeable technological progress that was induced by the tightened Japanese fuel economy standards. The estimated lower bounds of the effect mostly range from 3 to $5 \%$. That is, the regulation-induced technological progress in fuel efficiency improved the average Japanese vehicle's fuel economy by at least $3-5 \%$ relative to a counterfactual case of no regulatory change, holding constant other vehicle attributes and the production cost devoted to fuel economy. These lower bounds are roughly equivalent to the fuel economy improvement (conditional on other vehicle attributes) that would have occurred over 4-7 years even with no pressure from fuel economy regulations or fuel prices. These findings serve to illustrate that induced innovations that the previous studies have confirmed in patent data are indeed adopted in commercialized products and significantly improve actual environmental performance or energy efficiency.

Open Access This article is distributed under the terms of the Creative Commons Attribution 4.0 International License (http://creativecommons.org/licenses/by/4.0/), which permits unrestricted use, distribution, 
and reproduction in any medium, provided you give appropriate credit to the original author(s) and the source, provide a link to the Creative Commons license, and indicate if changes were made.

\section{References}

Acemoglu D, Aghion P, Bursztyn L, Hémous D (2012) The environment and directed technical change. Am Econ Rev 102(1):131-166

Aghion P, Dechezleprêtre A, Hémous D, Martin R, Reenen JV (2016) Carbon taxes, path dependency, and directed technical change: evidence from the auto industry. J Polit Econ 124(1):1-51

Alexander AJ, Mitchell BM (1985) Measuring technological change of heterogeneous products. Technol Change Social Change 27(2):161-195

Ambec S, Cohen MA, Elgie S, Lanoie P (2013) The porter hypothesis at 20: can environmental regulation enhance innovation and competitiveness? Rev Environ Econ Policy 7(1):2-22

Berry S, Kortum S, Pakes A (1996) Environmental change and hedonic cost functions for automobiles. Proc Natl Acad Sci 93(23):12731-12738

Brunnermeier SB, Cohen MA (2003) Determinants of environmental innovation in US manufacturing industries. J Environ Econ Manag 45(2):278-293

Calel R, Dechezleprêtre A (2016) Environmental policy and directed technological change: evidence from the European carbon market. Rev Econ Stat 98(1):173-191

Cameron AC, Trivedi PK (2005) Microeconometrics: methods and applications. Cambridge University Press, Cambridge

Carraro C, Cian ED, Nicita L, Massetti E, Verdolini E (2010) Environmental policy and technical change: a survey. Int Rev Environ Resour Econ 4(2):163-219

Crabb JM, Johnson DK (2010) Fueling innovation: the impact of oil prices and CAFE standards on energyefficient automobile technology. Energy J 31(1):199-216

Dechezleprêtre A, Sato M (2017) The impacts of environmental regulations on competitiveness. Rev Environ Econ Policy 11(2):183-206

Environmental Protection Agency (2018) Inventory of U.S. greenhouse gas emissions and sinks: 1990-2016. https://www.epa.gov/ghgemissions/inventory-us-greenhouse-gas-emissions-and-sinks-1990-2016. Accessed 1 April 2019

Environmental Protection Agency (2019) The 2018 EPA automotive trends report. https://www.epa.gov/autom otive-trends. Accessed 1 April 2019

Haščič I, de Vries F, Johnstone N, Medhi N (2009) Effects of environmental policy on the type of innovation: the case of automotive emission-control technologies. OECD J Econ Stud 2009(1):49-66

Hicks JR (1932) The theory of wages. Macmillan, London

Intergovernmental Panel on Climate Change (2014) Climate change 2014: mitigation of climate change. Contribution of working group III to the fifth assessment report of the Intergovernmental Panel on Climate Change. Cambridge University Press, Cambridge

Jaffe AB, Palmer K (1997) Environmental regulation and innovation: a panel data study. Rev Econ Stat 79(4):610-619

Jaffe AB, Newell RG, Stavins RN (2003) Technological change and the environment. In: Mäler K-G, Vincent JR (eds) Handbook of environmental economics Chapter 11, vol 1. Elsevier Science, Amsterdam, pp 461-516

Knittel CR (2011) Automobiles on steroids: product attribute trade-offs and technological progress in the automobile sector. Am Econ Rev 101(7):3368-3399

Lanjouw JO, Mody A (1996) Innovation and the international diffusion of environmentally responsive technology. Res Policy 25(4):549-571

National Research Council (2002) Effectiveness and impact of corporate average fuel economy standards. National Academy Press, Washington

Nesta L, Vona F, Nicolli F (2014) Environmental policies, competition and innovation in renewable energy. J Environ Econ Manag 67(3):396-411

Newell RG (1997) Environmental policy and technological change: the effects of economic incentives and direct regulation on energy-saving innovation. Ph.D. thesis, Harvard University

Newell RG, Jaffe AB, Stavins RN (1999) The induced innovation hypothesis and energy-saving technological change. Q J Econ 114(3):941-975

Popp D (2002) Induced innovation and energy prices. Am Econ Rev 92(1):160-180

Popp D (2006) International innovation and diffusion of air pollution control technologies: the effects of $\mathrm{NO}_{\mathrm{x}}$ and $\mathrm{SO}_{2}$ regulation in the US, Japan, and Germany. J Environ Econ Manag 51(1):46-71 
Popp D, Newell RG, Jaffe AB (2010) Energy, the environment, and technological change. In: Hall BH, Rosenberg N (eds) Handbook of the economics of innovation, Chapter 21, vol 2. Elsevier Science, Amsterdam, pp 873-937

Porter M (1991) America's green strategy. Sci Am 264(4):168

Triplett JE (1985) Measuring technological change with characteristics-space techniques. Technol Change Social Change 27(2):283-307

Vollebergh HRJ (2007) Differential impact of environmental policy instruments on technological change: a review of the empirical literature. Tinbergen Institute Discussion Paper

Publisher's Note Springer Nature remains neutral with regard to jurisdictional claims in published maps and institutional affiliations. 